\title{
EVALUASI DAYA DUKUNG TANAH DASAR UNTUK MENDUKUNG PENANGANAN KERUSAKAN RUAS JALAN WEELULI - FULUR KABUPATEN BELU - NTT
}

Oleh:

Welem Daga

Dosen Politeknik Negeri Kupang, Jl. Adisucipto Penfui - Kupang, e-mail : welem_d@yahoo.com

Melchior Bria

Dosen Politeknik Negeri Kupang, Jl. Adisucipto Penfui - Kupang, e-mail : melchibria@yahoo.co.id

Anastasia Muda

Dosen Politeknik Negeri Kupang, Jl. Adisucipto Penfui - Kupang, e-mail : anashendrian@yahoo.com

Ludofikus Dumin

Dosen Politeknik Negeri Kupang, Jl. Adisucipto Penfui - Kupang.

\begin{abstract}
Abstrak
Salah satu penyebab kegagalan struktur perkerasan jalan (pavement) dalam melayani arus lalulintas adalah daya dukung tanah (DDT) yang relatif rendah. Hal ini dapat diantisipasi sebelumnya melalui suatu penelitian tanah dasar pada ruas jalan baru maupun peningkatan jalan. Parameter yang paling umum dipakai dalam menilai daya dukung tanah untuk perkerasan jalan adalah nilai California Bearing Ratio (CBR) yang dapat diperoleh baik melalui uji CBR laboratorium atau uji Dynamic Cone Penetrometer (DCP) langsung di lapangan. Dalam penelitian ini akan dievaluasi bagaimana aplikasi dari kedua metode ini untuk menilai daya dukung tanah dasar dengan mengambil kasus di Ruas Jalan Weeluli - Fulur Kabupaten Belu NTT. Ruas jalan ini mengalami kerusakan yang cukup parah karena beban kendaraan yang melalui jalur ini melebihi kapasitas tonase jalan. Hasil dari penelitian ini adalah diperolehnya nilai DDT berdasarkan hasil uji lapangan menggunakan DCP dan hasil uji CBR laboratorium dan nantinya dipakai dalam merencanakan pekerjaan peningkatan ruas jalan Weeluli Fulur. Hasil perbandingan nilai CBR diperoleh hubungan antara CBR lapangan (y) dengan CBR Laboratorium $(x)$ adalah Linear menurut persamaan $y=1,249 x-0,557$.
\end{abstract}

\section{Hal 1}


Kata Kunci: Pavement, DDT, CBR, DCP. 1 PENDAHULUAN

\subsection{Latar Belakang}

Penanganan kerusakan jalan pada ruas-ruas jalan di hampir sebagian wilayah Provinsi Nusa Tenggara Timur, cenderung ditangani tanpa didahului suatu studi yang komprehensif. Akibatnya, metode atau teknik yang diterapkan menjadi tidak pas dan tidak menyelesaikan permasalahan secara tuntas.

Salah satu ruas jalan kabupaten di wilayah NTT yang mengalami hal tersebut adalah ruas jalan Weluli - Fulur. Ruas jalan ini merupakan salah satu ruas jalan penting yang menghubungkan antar wilayah di Kabupaten Belu bagian utara dan antar wilayah-wilayah tersebut dengan Atambua, Ibu Kota Kabupaten Belu dan merupakan akses utama ke pospos pengamanan perbatasan RI - Timor Leste.

Identifikasi Dinas Pekerjaan Umum Kabupaten Belu menunjukkan bahwa, setiap tahun pada beberapa titik, mengalami kerusakan jalan yang cukup parah. Sejauh ini evaluasi terhadap tanah dasar pada ruas jalan ini tidak dilakukan secara mendetail sehingga pendekatan perbaikan jalan kurang menjawab permasalahan yang ada.

Ada beberapa metode untuk menentukan daya dukung tanah seperti CBR (California Bearing Ratio), k (Modulus Reaksi Tanah Dasar), Mr (Resilient Modulus), DCP (Dynamic Cone Penetrometer) dan HCP (Hand Cone Penetrometer). Di Indonesia daya dukung tanah dasar untuk kebutuhan perencanaan tebal perkerasan jalan ditentukan dengan mempergunakan pemeriksaan CBR. CBR di peroleh dari hasil pemeriksaan sampel tanah yang telah disiapkan di laboratorium atau langsung di lapangan (Sukirman, 1999).

Pengujian dengan menggunakan DCP ini system kerjanya yaitu dengan cara dipukul/tumbuk, sedangkan pengujian CBR laboratorium yaitu dengan cara ditekan. Hasil pengujian DCP ini akan dibandingkan dengan cara mengkorelasikannya dengan CBR laboratorium dan kepadatan.

Untuk itulah maka penelitian dengan judul "Evaluasi Daya Dukung Tanah Dasar untuk Mendukung Penanganan Kerusakan Ruas Jalan Weeluli - Fulur Kabupaten Belu - NTT" perlu dilakukan guna memberikan suatu usulan metode perbaikan yang tepat.

\subsection{Permasalahan}

Berdasarkan uraian latar belakang diatas maka peneliti dapat menentukan

\section{Hal 2}


permasalahan yang akan diteliti yaitu bagaimana perbandingan nilai CBR hasil uji lapangan dan hasil uji laboratorium.

\subsection{Tujuan}

Secara umum penelitian ini dimaksudkan untuk mencari suatu solusi atas permasalahan penanganan ruas jalan yang mengalami kerusakan sehingga tujuan penelitian ini adalah untuk dapat memberikan perbandingan nilai CBR hasil uji lapangan dan hasil uji laboratorium.

\section{TINJAUAN PUSTAKA}

\subsection{Perkerasan Jalan}

Perkerasan adalah struktur yang terdiri dari beberapa lapisan dengan kekerasan dan daya dukung yang berlainan. Perkerasan yang dibuat dari campuran aspal dengan agregat, digelar di atas suatu permukaan material granular mutu tinggi disebut perkerasan lentur, sedangkan perkerasan yang dibuat dari slab-slab beton (Portland Cement Concrete ) disebut perkerasan "Rigid".

Perkerasan dibuat dengan tujuan untuk memberikan permukaan yang halus dan aman pada segala kondisi cuaca, serta ketebalan dari setiap lapisan harus cukup aman untuk menjamin bahwa yang bekerja tidak merusak perkerasan lapisan di bawahnya.
Perkerasan lentur terdiri dari satu lapisan bahan atau lebih yang digolongkan sebagai lapisan permukaan, lapisan pondasi, dan lapisan pondasi bawah yang terletak di atas lapisan tanah dasar yang telah dipersiapkan. Lapisan tanah dasar dapat berupa galian atau timbunan. Lapisan permukaan terdiri dari bahan berbitumen yang berfungsi untuk memberikan permukaan yang halus yang dapat memikul beban-beban yang bekerja dan berpengaruh pada lingkungan untuk jangka waktu operasional tertentu untuk menyebarkan beban yang bekerja kelapisan dibawahnya.

Lapisan pondasi atas adalah bahan yang terdiri dari material berbutir dengan bahan pengikat atau tanpa pengikat yang berfungsi memikul beban yang bekerja dan menyebarkan ke lapisan-lapisan dibawahnya.

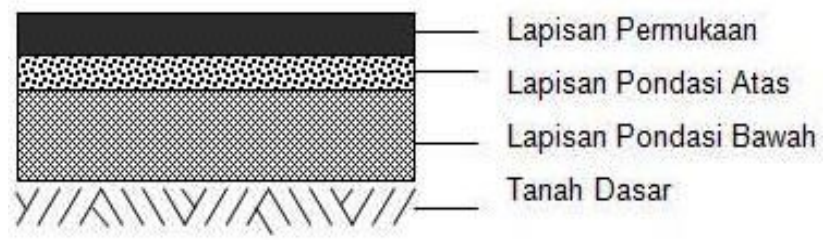

Gambar 1. Susunan Perkerasan Jalan

Fungsi perkerasan adalah untuk menyebarkan beban ke tanah dasar dan semakin besar kemampuan tanah dasar untuk memikul beban, maka tebal lapisan perkerasan yang dibutuhkan semakin kecil. Karena keseluruhan struktur 
perkerasan didukung sepenuhnya oleh tanah dasar, maka identifikasi dan evaluasi terhadap struktur tanah dasar adalah sangat penting bagi perencanaan tebal perkerasan.

\subsection{Tanah Dasar untuk Jalan Raya}

Tanah dasar merupakan tanah dimana perkerasan dibangun, sebagaimana halnya dengan bangunan sipil lainnya. Pada kasus yang sederhana, tanah dasar dapat terdiri atas tanah asli tanpa perlakuan; sedangkan pada kasus lain yang lebih umum, tanah dasar terdiri atas tanah asli pada galian atau bagian atas timbunan yang dipadatkan.

Sebagai prasarana transportasi darat, perkerasan harus mempunyai permukaan yang selalu rata dan kesat, agar para pengguna jalan dapat merasa nyaman dan aman (safe). Karena dibangun pada tanah dasar, maka kinerja perkerasan akan sangat dipengaruhi oleh mutu tanah dasar.

Dengan dituntutnya perkerasan yang harus selalu mempunyai permukaan yang rata, maka persyaratan utama yang harus dipenuhi tanah dasar adalah tidak mudah mengalami perubahan bentuk. Tanah dasar yang mengalami perubahan bentuk, baik akibat beban lalu-lintas maupun cuaca, akan mengakibatkan perkerasan mengaiami kerusakan (misal, gelombang, alur, penurunan) yang kemungkinan diikuti dengan terjadinya retak.

Perubahan bentuk tanah dasar dapat diakibatkan oleh kekuatan atau daya dukung yang rendah (tanah mudah runtuh), pengembangan, penyusutan dan densifikasi tanah dasar serta konsolidasi tanah di bawah tanah dasar. Lebih jauh lagi, faktor-faktor tersebut akan tergantung pada jenis tanah, berat isi kering dan kadar air (Pedoman Pekerjaan Tanah, Dinas Pekerjaan Umum, No: 003 - 02 / BM / 2006).

Menurut Spesifikasi, tanah dasar adalah lapisan paling atas dari timbunan badan jalan setebal $30 \mathrm{~cm}$, yang mempunyai persyaratan tertentu sesuai fungsinya, yaitu yang berkenaan dengan kepadatan dan daya dukungnya (CBR).

Lapisan tanah dasar dapat berupa tanah asli yang dipadatkan jika tanah aslinya baik, atau tanah urugan yang didatangkan dari tempat lain atau tanah yang distabilisasi dan lain lain.

Ditinjau dari muka tanah asli, maka lapisan tanah dasar dibedakan atas:

- Lapisan tanah dasar, tanah galian.

- Lapisan tanah dasar, tanah urugan.

- Lapisan tanah dasar, tanah asli.

Kekuatan dan keawetan konstruksi perkerasan jalan sangat tergantung dari sifat-sifat dan daya dukung tanah dasar. 
Umumnya persoalan yang menyangkut tanah dasar adalah sebagai berikut :

- Perubahan bentuk tetap (deformasi permanen) akibat beban lalu lintas.

- Sifat mengembang dan menyusutnya tanah akibat perubahan kadar air.

- Daya dukung tanah yang tidak merata akibat adanya perbedaan sifat-sifat tanah pada lokasi yang berdekatan atau akibat kesalahan pelaksanaan misalnya kepadatan yang kurang baik.

Tidak semua tanah layak sebagai pondasi dari bangunan yang ada di atasnya. Pada tanah lunak, tanah berawa dan reklamasi, sebelum dibangun suatu konstruksi di atasnya, tanah-tanah tersebut harus terlebih dahulu distabilisasi. Tujuannya agar bangunan yang berdiri di atasnya tidak mengalami penurunan sehingga kegagalan struktur akibat rendahnya daya dukung tanah dapat dihindari. Namun demikian, Mochtar (2004) mengemukakan, penerapan teknologi perbaikan tanah sangat tergantung pada jenis tanahnya. Karena itu, sangat diperlukan pemahaman tentang berbagai tekonologi perbaikan tanah dan kesesuaian penerapannya.

Menurut Mitchell dalam Mochtar (2004), perbaikan tanah tersebut meliputi

1. Pemadatan tanah dalam (deep compaction) dengan menggunakan penumbuk berat dan ledakan (blasting). Pemadatan untuk tanah permukaan secara lapis demi lapis tidak dibahas disini.

2. Pemadatan tanah (soil precompression), terutama yang menyangkut pemambatan tanah awal (pre compression) dengan pembebanan awal (preloading) dan penggunaan drain-darain vertikal (vertical drain), serta pemampatan tanah cara electro osmosis.

3. Injeksi dan grouting kedalam tanah untuk memperkuat tanah dasar dan menstabilkan struktur tanahnya.

4. Stabilisasi tanah dengan bantuan bahan luar (tambahan) atau dengan bantuan bahan-bahan kimia yang dicampur ke tanah asli.

5. Stabilisasi cara thermal.

6. Pemberian perkuatan dalam tanah (reinforcement), baik reinforcement tarik maupun tekan. Disini juga diberikan uraian tentang penggunaan bahan geosinthesis.

\subsection{California Bearing Ratio (CBR)}

Metode rasio daya dukung california (California Bearing Ratio $=$ CBR Method $)$ mula diciptakan oleh 0 . J. Porter, kemudian dikembangkan oleh California State Highway Departement, tetapi kemudian dikembangkan dan dimodifikasi

\section{Hal 5}


oleh Corps insiyur-insiyur tentara Amerika Serikat ( U.S. Army Corps of Engineers).

Metode ini mengkombinasikan percobaan pembebanan penetrasi laboratorium atau di lapangan dengan rencana empiris (emperical design charts) untuk menentukan tebal lapisan perkerasan. Hal ini digunakan sebagai metode perencanaan perkerasan lentur (flexible pavement) jalan dan lapangan terbang. Tebal bagian perkerasan ditentukan oleh nilai CBR.

CBR laboratorium ialah perbandingan antara beban penetrasi suatu bahan terhadap bahan standar dengan kedalaman dan kecepatan penetrasi yang sama (SNI SNI 03-17441989).

CBR menurut RSNI3 $1738: 2008$ didefinisikan sebagai perbandingan antara tegangan penetrasi suatu lapisan/bahan tanah atau perkerasan terhadap tegangan penetrasi bahan standar dengan kedalaman dan kecepatan penetrasi yang sama (dinyatakan dalam persen)

CBR juga didefinisikan sebagai perbandingan antara beban percobaan ( Test Load ) dengan beban standar (Standard Load) dan dinyatakan dalam persentase. Lebih jelas dapat dinyatakan dengan persamaan :
$C B R=\frac{\mathrm{Pt}}{\mathrm{PS}} \times 100 \%$

Dalam hal ini :

$$
\mathrm{Pt}=\text { Beban percobaan ( Test Load) }
$$

Ps = Beban standar ( Standard Load) Harga CBR adalah nilai yang menyatakan kualitas tanah dasar dibandingkan dengan bahan standar berupa batu pecah yang mempunyai nilai CBR sebesar $100 \%$ dalam memikul beban lalu lintas CBR lapangan digunakan untuk :

a. Memperoleh nilai CBR asli di lapangan, sesuai dengan kondisi tanah dasar saat itu. Umum digunakan untuk perencanaan tebal perkerasan yang lapisan tanah dasarnya sudah tidak akan dipadatkan lagi. Pemeriksaaan dilakukan dalam kondisi kadar air tanah tinggi (musim penghujan) atau dalam kondisi terburuk yang mungkin terjadi

b. Memeriksa apakah kepadatan yang diperoleh sesuai dengan yang diinginkan. Pemeriksaan untuk tujuan ini tidak umum digunakan, lebih sering menggunakan pemeriksaan yang lain seperti kerucut pasir (Sand Cone) dan lain-lain

CBR lapangan ialah perbandingan antara beban penetrasi suatu lapisan/bahan tanah atau perkerasan terhadap bahan standar dengan kedalaman dan kecepatan penetrasi yang sama. Nilai CBR lapangan pada umumnya digunakan untuk perencanaan lapis tambahan

\section{Hal 6}


(overlay).

2.4 Dynamic Cone Penetrometer Test (DCP)

Dynamic Cone Penetrometer Test (DCP) pertama kali dikembangkan di Australia oleh Scala (1956). DCP yang sekarang merupakan alat yang dikembangkan dari the Transvaal Roads Department in South Africa (Luo, 1998). DCP mekanis merupakan perpaduan dari uji insitu testing yaitu CPT dan SPT.

Menentukan nilai CBR lapangan dengan menggunakan data DCP (Dynamic Cone Penetrometer) mulai digunakan di Indonesia sejak tahun 1985 / 1986. Pemeriksaan dengan DCP menghasilkan data kekuatan tanah sampai $90 \mathrm{~cm}$ di bawah tanah dasar.

Menurut Wesley (1988) Untuk menentukan nilai CBR sub base atau base course suatu perkerasan secara cepat dan praktis. Biasa dilakukan sebagai pekerjaan quality control pekerjaan pembuatan jalan dapat menggunakan dengan alat DCP.

Tujuan dari pengujian DCP adalah :

(i) agar dapat menyelidiki tebal dan jenis bahan untuk setiap lapis perkerasan dan

(ii) untuk mengukur pengaruh pemadatan yang disebabkan oleh lalu-lintas normal.
Tabel 1 : Klasifikasi Nilai CBR

\begin{tabular}{|c|c|}
\hline CBR (\%) & Keterangan \\
\hline $0-3$ & sangat buruk \\
\hline $3-7$ & buruk \\
\hline $7-20$ & sedang \\
\hline $20-50$ & baik \\
\hline$>50$ & sangat baik \\
\hline
\end{tabular}

Dalam melakukan penekanan konus DCP dibantu hammer yang dijatuhkan pada ketinggian tertentu dengan jumlah tumbukan tertentu metode ini identik dengan SPT yaitu dalam mencari number of blow (N). Sedangkan bacaan DCP diukur berdasarkan kedalaman penekanan konus (depth penetration) identik dengan CPT dalam membaca tiap interval tertentu konus dan gesekan (friction) selimut konus.

Pengujian dilakukan dengan menggunakan alat seperti tampak pada gambar 3. Penumbuk dengan berat $=20$ lb $(9,072 \mathrm{~kg})$ dijatuhkan dari ketinggian 20 inci $(50,8 \mathrm{~cm})$ dengan bebas melalui sebuah pipa berdiameter 0,625 inchi $(15,875 \mathrm{~mm})$ yang ditahan oleh landasan (anvi). Ujung pipa baja berbentuk kerucut dengan luas $=0,50$ dengan sudut puncak $=30^{\circ}$ atau $60^{\circ}$. 


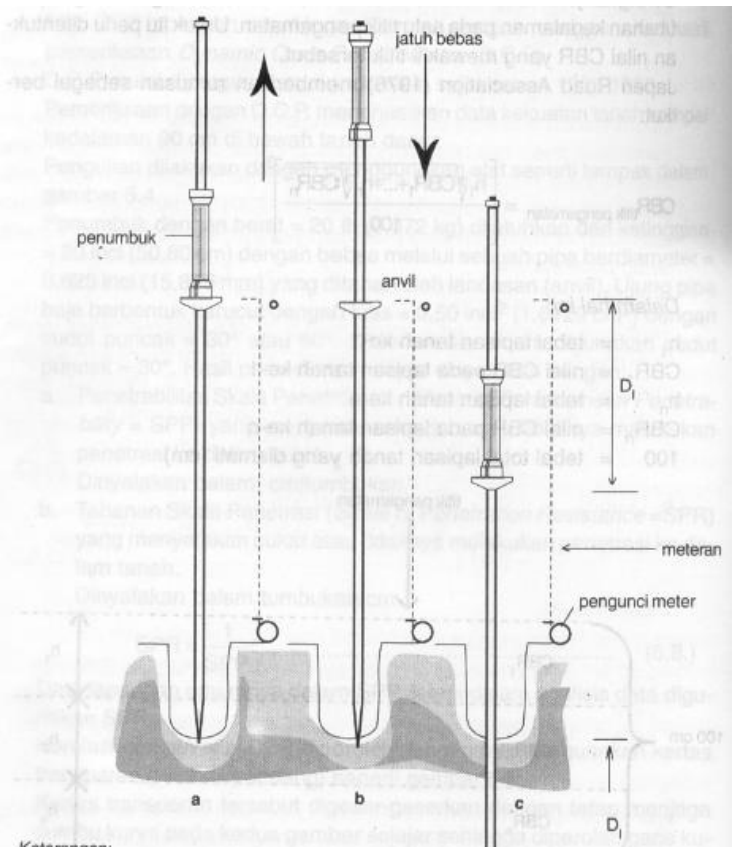

Gambar 2. Skema Kerja Alat Uji DCP

\section{METODE}

\subsection{Alat}

- Alat uji DCP

- Mould / tabung sampel sampel undistubed

- Pengujian CBR Lab tanah asli (Undisturbed) dan tanah terganggu (ASTM 1883)

- Satu set alat uji Klasifikasi tanah (Analisis saringan (ASTM D 422), Atterberg limit (ASTM D 4318), hydrometer (ASTM D1140)

\subsection{Bahan}

Tanah di ambil dari bahu jalan pada ruas jalan Weeluli - Fulur dengan jarak antar titik 100-150 meter, dengan masingmasing 3 sampel untuk setiap jenis uji laboratorium

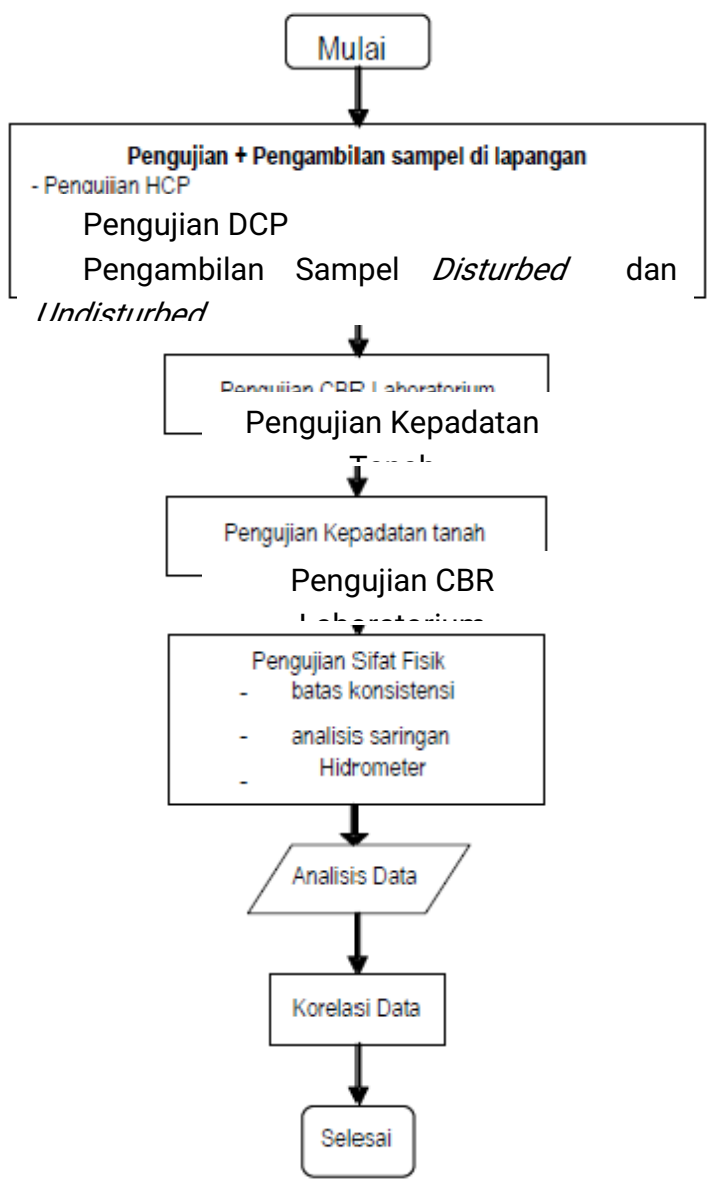

Gambar 3. Bagan Alir Metodologi Penelitian

\section{HASIL DAN PEMBAHASAN}

4.1 Uji Lapangan

Uji lapangan terhadap ruas jalan WeeluliFulur Kabupaten Belu mencakup 
beberapa hal yang berhubungan dengan perencanaan jalan raya. Hal-hal yang disurvey dan diuji mengacu pada perencanaan ruas jalan menurut Standar Survey dan Perencanaan Jalan yang dikeluarkan oleh Bina Marga.

Survey dan uji lapangan yang dilakukan untuk menilai tanah dasar pada ruas halan Weeluli-Fulur ini meliputi :

1. Survey Lalulintas

Hasil survey pada ruas jalan WeeluliFulur diperoleh data sebagai berikut :

- Nama Ruas Jalan : Weluli - Fulur

- Lebar Jalan : 4 meter

- Panjang Jalan : 5,00 km ( STA $0 \pm 0.00$ - STA $5+0.00$ )

- Fungsi Jalan : Jalan Kabupaten

- Kelas Jalan : III /C

- Jenis Pekerasan : Lapen

2. Survey Tanah Dasar, meliputi Uji DCP, Pengambilan Sampel Tanah Tidak Terganggu dengan Tabung Sampel.

Titik pengujian digambarkan dalam Gambar 4 berikut.

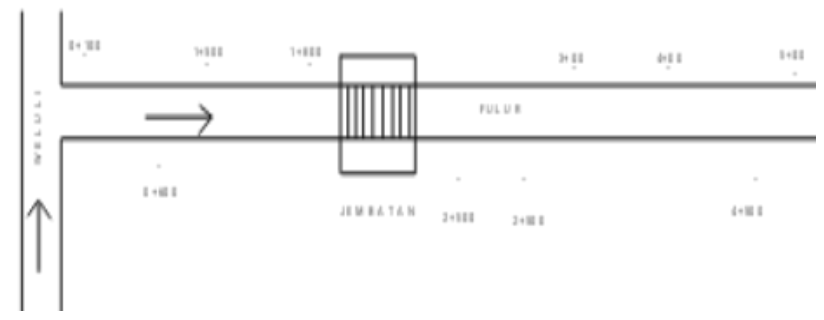

Gambar 4. Lokasi Titik Pengujian DCP Hasil uji DCP pada titik $0+100$ diruas jalan Weeluli - Fulur dapat ditampilkan sebagai berikut :

Tabel 2. Hasil Uji DCP

\begin{tabular}{|c|c|c|c|c|c|}
\hline $\begin{array}{c}\text { Jlh } \\
\text { Tum- } \\
\text { bukan }\end{array}$ & $\begin{array}{l}\text { Kum. } \\
\text { Tumb } \\
\text { ukan }\end{array}$ & $\begin{array}{l}\text { Pene- } \\
\text { trasi } \\
(\mathrm{mm})\end{array}$ & $\begin{array}{l}\text { Kum. } \\
\text { Penetra } \\
\text { si (mm) }\end{array}$ & $\begin{array}{c}\text { DCP } \\
(\mathrm{mm} / \mathrm{tu} \\
\text { mbukan } \\
\text { ) }\end{array}$ & $\begin{array}{l}\text { CBR } \\
(\%)\end{array}$ \\
\hline 0 & 0 & 5 & 0 & \multirow{5}{*}{7.00} & \multirow{5}{*}{$\begin{array}{c}50.5 \\
7\end{array}$} \\
\hline 5 & 5 & 35 & 30 & & \\
\hline 5 & $0^{1}$ & 65 & 60 & & \\
\hline 5 & $5^{1}$ & 90 & 85 & & \\
\hline 5 & $0^{2}$ & 145 & $0^{14}$ & & \\
\hline 5 & $5^{2}$ & 240 & $5^{23}$ & \multirow{4}{*}{24.15} & \multirow{4}{*}{9.95} \\
\hline 5 & $0^{3}$ & 370 & $\begin{array}{l}36 \\
5\end{array}$ & & \\
\hline 5 & $5^{3}$ & 460 & $\begin{array}{l}45 \\
5\end{array}$ & & \\
\hline 5 & $0^{4}$ & 628 & $3^{62}$ & & \\
\hline
\end{tabular}

\section{Hal 9}




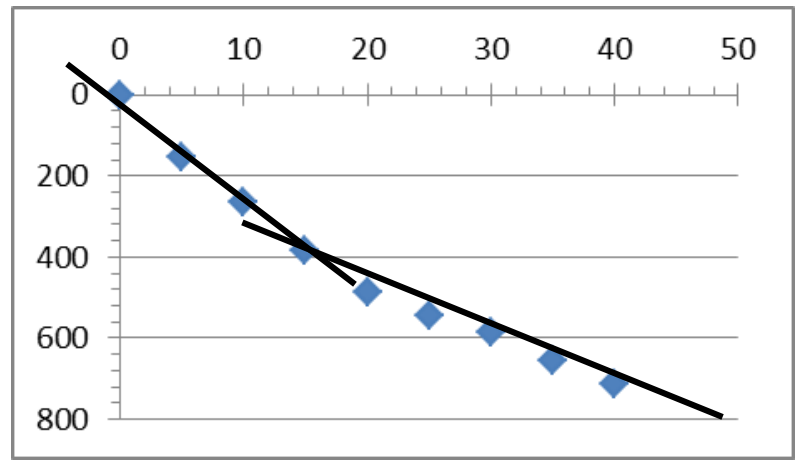

Gambar 5. Grafik Uji DCP

Dari hasil ini terlihat bahwa nilai CBR pada kedalaman pengujian $235 \mathrm{~mm}=9,95 \%$ dibawah tanah merupakan nilai CBR tanah asli sedangkan nilai CBR 50,57\% merupakan bahu jalan atau tanah yang telah digilas atau dibebani sebelumnya.

Hasil uji pada titik-titik sampel selanjutnya ditampilkan dalam rekapan hasil uji DCP lalu dikorelasikan menjadi nilai CBR pada tabel hasil uji dengan mengambil nilai CBR tanah dasarnya saja.

Tabel 3. Rekapitulasi Nilai CBR berdasarkan uji DCP pada Ruas Jalan Weeluli - Fulur

\begin{tabular}{|c|c|c|c|}
\hline $\begin{array}{c}\text { Nomor } \\
\text { Titik }\end{array}$ & $\begin{array}{c}\text { Lokasi / } \\
\text { Sta. }\end{array}$ & $\begin{array}{c}\text { DCP } \\
\text { (mm/tumbu } \\
\text { kan) }\end{array}$ & CBR (\%) \\
\hline Titik 1 & $0+100$ & 24,15 & 9,95 \\
\hline Titik 2 & $0+600$ & 30,24 & 7,40 \\
\hline Titik 3 & $1+500$ & 20,29 & 12,54 \\
\hline Titik 4 & $1+800$ & 29.75 & 7.57 \\
\hline Titik 5 & $2+100$ & 17,80 & 14,85 \\
\hline
\end{tabular}

\begin{tabular}{|c|c|c|c|}
\hline Titik 6 & $2+500$ & 28,34 & 8,06 \\
\hline Titik 7 & $3+100$ & 28,88 & 7,87 \\
\hline Titik 8 & $4+000$ & 23,80 & 10,14 \\
\hline Titik 9 & $4+600$ & 18,25 & 14,37 \\
\hline Titik 10 & $5+000$ & 28,90 & 7,86 \\
\hline
\end{tabular}

Dari hasil uji DCP ini terlihat bahwa pada ruas Jalan Weeluli-Fulur mempunyai nilai CBR berkisar antara 7\% - 14\% yang artinya kondisi tanah masuk kategori "Sedang" atau kalau dikorelasikan ke Daya Dukung Tanah (DDT) pada perkerasan jalan maka masuk dalam syarat minimum CBR.

\subsection{Pengujian Laboratorium}

Uji laboratorium yang dilakukan meliputi :

1. Pengujian kadar air

Pengujian kadar air dilakukan pada sampel tanah dasar yang tidak terganggu (undisturbed).

\begin{tabular}{|c|c|c|}
\hline Lokasi Titik & $\begin{array}{c}\text { Kadar Air } \\
(\%)\end{array}$ & Keterangan \\
\hline STA. $0+100$ & 9,01 & \multirow{10}{*}{$\begin{array}{c}\text { Kadar air asli } \\
\text { pada tanah } \\
\text { dasar } \\
\text { diperhitungaka } \\
\text { n dalam uji } \\
\text { pemadatan/pro } \\
\text { ctor dan CBR } \\
\text { lab. }\end{array}$} \\
\hline STA. $0+600$ & 5,59 & \\
\hline STA. $1+500$ & 15,28 & \\
\hline STA. $1+800$ & 17,92 & \\
\hline STA. $2+100$ & 18,44 & \\
\hline STA. $2+500$ & 18,93 & \\
\hline STA. $3+100$ & 20,64 & \\
\hline STA. 4+00 & 35,24 & \\
\hline STA. $4+600$ & 17,61 & \\
\hline STA. $5+00$ & 15,95 & \\
\hline
\end{tabular}

Dari hasil pengujian pada sampel uji diperoleh kadar air $(w)$ terukur rata-rata berkisar antara $5 \%$ sampai dengan $35 \%$. 
2. Pengujian berat jenis

Pengujian berat jenis dilakukan pada sampel tanah dasar yang terganggu (disturbed) dan tidak terganggu (undisturbed).

Tabel 5. Rekapitulasi Berat Jenis (Gs) tanah Ruas Jalan Weeluli-Fulur

\begin{tabular}{|c|c|c|c|c|c|}
\hline No & \multicolumn{2}{|c|}{ Lokasi Titik } & LL (\%) & $\mathrm{PL}(\%)$ & $\mathrm{IP}(\%)$ \\
\hline 1 & \multicolumn{2}{|c|}{ STA. $0+100$} & 45,2 & 28,6 & 16,6 \\
\hline 2 & \multicolumn{2}{|c|}{ STA. $0+600$} & 44,3 & 28,7 & 15,6 \\
\hline 3 & \multicolumn{2}{|c|}{ STA. $1+500$} & 59 & 33 & 26 \\
\hline 4 & \multicolumn{2}{|c|}{ STA. $1+800$} & 48,4 & 29 & 19,4 \\
\hline 5 & \multicolumn{2}{|c|}{ STA. $2+100$} & 49,9 & 35,4 & 14,5 \\
\hline 6 & \multicolumn{2}{|c|}{ STA. $2+500$} & 43 & 21 & 22 \\
\hline 7 & \multicolumn{2}{|c|}{ STA. $3+100$} & 51,6 & 31,7 & 19,9 \\
\hline 8 & \multicolumn{2}{|c|}{ STA. 4+000 } & 52,2 & 39,2 & 13 \\
\hline 9 & \multicolumn{2}{|c|}{ STA. $4+600$} & 44 & 23,21 & 20,89 \\
\hline 10 & \multicolumn{2}{|c|}{ STA. 5+000 } & 47,8 & 25,7 & 22,1 \\
\hline \multicolumn{2}{|c|}{ Lokasi Titik } & \multicolumn{2}{|c|}{$\begin{array}{c}\text { Berat } \\
\text { Jenis (Gs) }\end{array}$} & \multicolumn{2}{|c|}{ Keterangan } \\
\hline \multicolumn{2}{|c|}{$\begin{array}{l}\text { STA. } \\
0+100\end{array}$} & \multicolumn{2}{|c|}{2,65} & \multirow{3}{*}{\multicolumn{2}{|c|}{$\begin{array}{l}\text { Berat jenis }(G) \\
\text { tanah dasar akan } \\
\text { diperhitungakan } \\
\text { dalam uji } \\
\text { pemadatan/proct } \\
\text { or dan CBR lab. }\end{array}$}} \\
\hline \multicolumn{2}{|c|}{$\begin{array}{l}\text { STA. } \\
0+600\end{array}$} & \multicolumn{2}{|c|}{2,72} & & \\
\hline \multicolumn{2}{|c|}{$\begin{array}{l}\text { STA. } \\
1+500\end{array}$} & \multicolumn{2}{|c|}{2,74} & & \\
\hline \multicolumn{2}{|c|}{$\begin{array}{l}\text { STA. } \\
1+800\end{array}$} & \multicolumn{2}{|c|}{2,59} & & \\
\hline \multicolumn{2}{|c|}{$\begin{array}{l}\text { STA. } \\
2+100\end{array}$} & \multicolumn{2}{|c|}{2,69} & & \\
\hline \multicolumn{2}{|c|}{$\begin{array}{l}\text { STA. } \\
2+500\end{array}$} & 2,5 & & & \\
\hline & & 2,6 & & & \\
\hline
\end{tabular}

\begin{tabular}{|c|c|c|}
\hline $3+100$ & & \\
\hline $\begin{array}{l}\text { STA. } \\
4+000\end{array}$ & 2,64 & \\
\hline $\begin{array}{l}\text { STA. } \\
4+600\end{array}$ & 2,61 & \\
\hline $\begin{array}{l}\text { STA. } \\
5+000\end{array}$ & 2,63 & \\
\hline
\end{tabular}

Dari hasil pengujian pada sampel uji diperoleh berat jenis atau berat spesifik $(G)$ rata-rata berkisar antara 2,65 sampai dengan 2,74 .

3. Pengujian Batas Atterberg

Pengujian berat jenis dilakukan pada sampel tanah dasar yang terganggu (disturbed) dan tidak terganggu (undisturbed).

Tabel 6. Rekapitulasi Uji Atterberg pada ruas jalan Weluli-Fulur

Dari hasil pengujian Batas Atterberg pada sampel uji diperoleh Indeks Plastisitas $(P)$ rata-rata berkisar antara $13 \%$ sampai dengan $22 \%$.

4. Analisa ukuran butiran tanah

Pengujian analisa saringan dilakukan pada sampel tanah dasar yang terganggu (disturbed) dan tidak terganggu (undisturbed). Dari hasil pengujian Analisa Saringan pada sampel uji diperoleh Tanah Dasar pada Ruas Jalan Weeluli - Fulur masuk dalam kategori jenis tanah A-7 dan A-6 menurut Klasifikasi Tanah AASHTO (untuk jalan raya). 
Berdasarkan nilai Indeks Plastisitas maka tanah pada ruas jalan WeluliFulur termasuk tanah lempung dan termasuk dalam kelompok A-7-5 dan A -7-6 menurut klasifikasi AASHTO. Sedangkan dilihat dari nilai Indeks Kelompok maka tersebut merupakan tanah dengan kondisi jelek sampai sangat jelek untuk digunakan sebagai tanah-dasar.

5. Pengujian CBR Laboratorium

Pengujian CBR laboratorium dilakukan pada sampel tanah dasar yang terganggu (disturbed) tanpa rendaman. Uji CBR ini dilakukan dengan tujuan mengetahui nilai CBR dimana nilai tersebut diperoleh dari perbandingan antara beban penetrasi terhadap beban standar dengan kedalaman dan kecepatan penetrasi yang sama.

Untuk uji CBR lab, digunakan standar SNI 03-1744-1989 tanpa rendaman (unsoacked), sampel yang dilakukan pengujian ini adalah sampel tanah pada semua titik pengambilan sampel atau sebanyak 10 titik. Hasil uji CBR pada titik 1 (Sta. 0+100) seperti ditunjukkan pada Gambar 6.

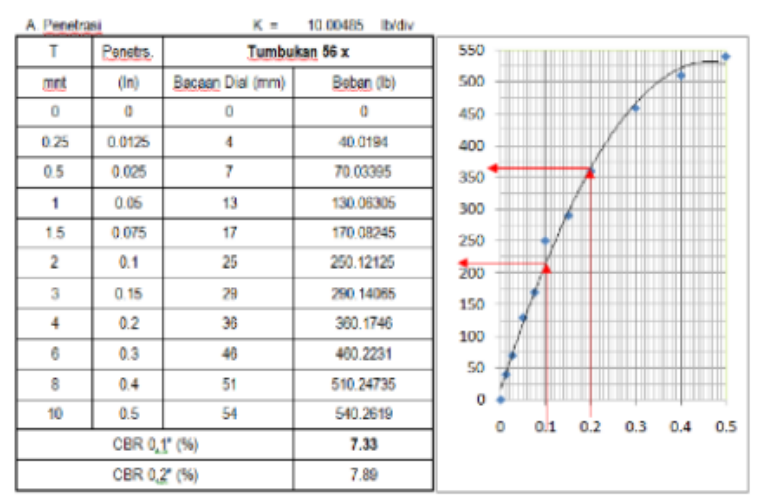

Gambar 6. Hasil Uji CBR Laboratorium

Tabel 7. Hasil Nilai CBR berdasarkan Uji CBR Laboratorium (Unsoacked)

\begin{tabular}{|c|c|c|}
\hline Lokasi Titik & CBR (\%) & Keterangan \\
\hline STA. $0+100$ & 7,33 & CBR 0,1" \\
\hline STA. $0+600$ & 6,85 & CBR 0,1" \\
\hline STA. $1+500$ & 9,34 & CBR 0,1" \\
\hline STA. $1+800$ & 6,40 & CBR 0,1" \\
\hline STA. $2+100$ & 12,50 & CBR 0,1" \\
\hline STA. 2+500 & 6,87 & CBR 0,1" \\
\hline STA. $3+100$ & 7,68 & CBR 0,1" \\
\hline STA. 4+000 & 9,40 & CBR 0,1" \\
\hline STA. 4+600 & 11,84 & CBR 0,1" \\
\hline STA. 5+000 & 6,78 & CBR 0,1" \\
\hline
\end{tabular}

Dari hasil pengujian CBR pada sampel uji diperoleh Tanah Dasar pada Ruas Jalan Weeluli - Fulur mempunyai nilai CBR antara $6 \%$ sampai dengan $12 \%$.

\subsection{Analisis Perbandingan CBR Lapangan dan CBR Laboratorium \\ Perbandingan hasil nilai CBR lapangan}


yang diperoleh dari hasil uji DCP terhadap nilai CBR laboratorium secara langsung dapat ditampilkan dalam grafik perbandingan hasil sebagai berikut.

Grafik Perbandingan Nilai CBR lapangan dan Nilai CBR Laboratorium

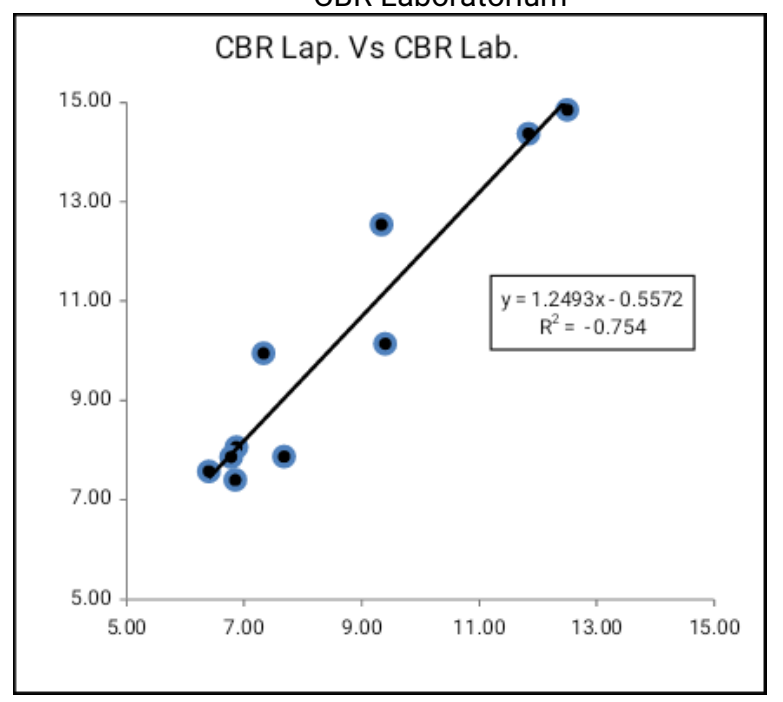

Dari grafik diperoleh hubungan antara CBR lapangan (y) dengan CBR Laboratorium $(x)$ adalah Linear menurut persamaan $\boldsymbol{y}=\mathbf{1 , 2 4 9} x-0,557$.

\section{REFERENSI}

Annual Book of ASTM Standards, 1997, "Standard Test Method for CBR (California Bearing Ratio) of Laboratory-Compacted Soils, Annual Book of ASTM Standards, 1997, "Standard Test Method for Particle-
Size analysis of Soils, ASTM D 422", West Conshohocken, PA.

Annual Book of ASTM Standards, 1997, "Standard Test Method for Liquid Limit, Plastic Limit, and Plasticity Index of Soils, ASTM

Annual Book of ASTM Standards, 1997, "Standard Test Method for Laboratory Determination of Water (Moisture) Content of Soil and Rock, ASTM D 2216", West Conshohocken, PA.

Bowles (1984), Sifat-sifat Fisis dan Geoteknik Tanah, Erlangga, Jakarta Hardiyatmo, H. C. (2006), Mekanika Tanah I, Gadjah Mada University Press, Jogjakarta

Hendarsin, Shirley L., 2000, "Perencanaan Teknik Jalan Raya, Cetakan Pertama", Bandung : Politeknik Negeri Bandung Jurusan Teknik Sipil.

Indrawan, Benny, 2004, "Optimalisasi Penggunaan DCP (Dynamic Cone Penetrometer) dalam Penentuan Nilai CBR, Kadar Air dan Kepadatan". Skripsi Jurusan Teknik Sipil. Pekanbaru : Universitas Riau.

Mochtar, I. B (2004), Teknologi Perbaikan Tanah Masa Kini, ITS, Surabaya

Mochtar, I.B (2004), Permasalahan Geoteknik pada Pembangunan Jalan, Makalah, ITS, Surabaya

Nakazawa, dkk (2002), Mekanika Tanah \& Teknik Pondasi, Pradnya Paramita, Jakarta 
Sukirman, Silvia, 1999, "Perkerasan Lentur Jalan Raya", Bandung : Nova. Nova, Bandung.
Qunik Wiqoyah, dkk (2006), Dinamika TEKNIK SIPIL, Volume 6, Nomor 2, Juli 2006 : $77-86$, UMS Surakarta 
